\title{
A PANDEMIA DO CORONAVÍRUS E OS GRUPOS VULNERÁVEIS: UMA ANÁLISE QUANTO À EFICÁCIA DOS ATOS DO GOVERNO BRASILEIRO
}

\begin{abstract}
THE PANDEMIC OF CORONAVIRUS AND THE VULNERABLE GROUPS: AN ANAL YSIS ABOUT THE EFFICIENCY OF BRAZILIAN GOVERNMENT ACTS
\end{abstract}

\author{
Maria Helena Lourenço Tamanini* \\ Giovanna Mayer Zorzeto* \\ Aline Regina das Neves ${ }^{* * *}$
}

\begin{abstract}
Resumo: $O$ presente trabalho analisa as medidas tomadas pelo Estado brasileiro para a contenção dos danos sofridos por grupos em vulnerabilidade social diante da epidemia causada pelo coronavírus, também conhecido como COVID-19. Verifica-se, por meio do levantamento de dados epidemiológicos, organizados por critérios cronológicos e sociais, a possibilidade de comparação dos impactos causados pela pandemia e das manifestações presidenciais e medidas administrativas. Neste sentido, mediante a identificação dos grupos sociais tidos como vulneráveis e de seus direitos e necessidades de proteções específicas, analisar-se-á os atos realizados pelo Estado, assim como sua postura, na busca da proteção destes grupos em vulnerabilidade. A pesquisa e elaboração do tema teve por base o método de estudo documental, por meio da identificação de legislação, doutrinas e jurisprudências, bem como do levantamento de dados de pesquisas relacionadas à pandemia. Assim, considerada a atual situação brasileira e mundial de enfrentamento ao COVID-19, pretende-se esclarecer se a atuação do Estado brasileiro na proteção dos grupos vulneráveis correspondeu aos deveres e diretrizes existentes, assim como se atenderam a necessidade desta população.
\end{abstract}

Palavras-chave: Pandemia. Coronavírus. Grupos Vulneráveis. Políticas Públicas. Medidas administrativas.

Abstract: The present paper analyzes the acts taken by the Brazilian government in order to contain the damage suffered by groups in social vulnerability, in face of the epidemic caused by coronavirus, also known as COVID-19. Through the survey of epidemiological data, organized by chronological and social criteria, it is possible to compare the impacts caused by the pandemic and the presidential manifestations and administrative acts. In this sense, it will analyze the actions taken by the Brazilian State in search of protection to the vulnerable groups, by identifying the social groups considered to be vulnerable and their rights and needs for specific protections. The research and elaboration of the theme was based on the method of

\footnotetext{
* Graduanda em Direito pela Universidade Estadual de Londrina, Londrina, Paraná, Brasil. E-mail: mariahtamanini@gmail.com.

** Graduanda em Direito pela Universidade Estadual de Londrina, Londrina, Paraná, Brasil. E-mail: gi.mayer.zorzeto@hotmail.com.

*** Doutoranda em Ciência Jurídica pela Universidade Estadual do Norte do Paraná, Jacarezinho, Paraná, Brasil. Mestre em Ciências Jurídicas pela Universidade Estadual do Norte do Paraná, Jacarezinho, Paraná, Brasil. Graduação em Direito pela Universidade Estadual de Londrina, Londrina, Paraná, Brasil. E-mail: alineneves@uel.br.
} 
documentary study, through the identification of legislation, doctrines and jurisprudence, as well as the collection of research data related to the pandemic. Thus, considering the current Brazilian and global situation of confronting COVID-19, it is intended to clarify whether the Brazilian State's action in protecting vulnerable groups corresponded to the existing duties and guidelines, as well as meeting the needs of this population.

Keywords: Pandemic. Coronavirus. Vulnerable Groups. Public Policies. Administrative Measures. 


\section{INTRODUÇÃO}

A discussão acerca da proteção aos direitos fundamentais dos seres humanos é temática constantemente em debate. Contudo, frente aos desafios que se apresentam devido à crise sanitária, hospitalar e financeira causada pela doença viral COVID-19, aqui também referida como coronavírus e COVID, eleva-se exponencialmente a importância do tema.

Segundo informações disponibilizadas pelo site do Ministério da Saúde (BRASIL, 2020a), o coronavírus foi inicialmente identificado em Wuhan, na China, em dezembro de 20 19. O vírus rapidamente passou a ser disseminado por meio da transmissão de pessoa para pessoa, pelo contato com superfícies infectadas, saliva, espirros, tosse e/ou catarro.

Mesmo antes do primeiro caso no Brasil, em fevereiro de 2020, já se podia sentir os impactos causados na população pela sensação de incerteza gerada com a disseminação de um novo vírus em escala global. Em resposta a situação, no mesmo mês, o governo brasileiro sancionou a Lei n. ${ }^{0}$ 13.979/2020 (BRASIL, 2020b), conhecida como Lei de Quarentena. Já no mês de março de 2020, a Organização Mundial da Saúde (OMS) (WORLD HEALTH ORGANIZATION, 2020) declarou que o número de contaminados pelo COVID-19 a nível global se elevou razoavelmente, devendo a situação ser tratada como uma pandemia.

Apesar do grande número de contaminados e da fácil transmissão do vírus, até o momento o COVID-19 ainda é considerado algo novo para os cientistas, que não possuem conhecimento pleno sobre a forma de contaminação do vírus, suas mutações, tratamentos e possibilidade de imunização. Enquanto o mundo espera pelo desenvolvimento das prometidas vacinas, o número de contaminados aumenta, assim como os danos secundários decorrentes da pandemia.

Dessa forma, verifica-se que a pandemia do COVID-19 causou impactos na realidade de todas as pessoas. Entretanto, certos grupos sociais foram muito mais afetados.

Em razão do exposto, verifica-se a necessidade de identificar as medidas empregadas pelo Estado brasileiro para a proteção dos grupos em vulnerabilidade social, apontando as obrigações do Estado nessa proteção. 
Para isso, esse trabalho se utilizará da metodologia de estudo documental, através da análise de doutrinas, legislações, medidas administrativas, resultados de pesquisas econômico-sociais no Brasil e das posturas governamentais, desde o início do coronavírus. Assim, iniciará fazendo a distinção dos grupos em vulnerabilidade social, de suas realidades e seus direitos, além dos prejuízos enfrentados devido à pandemia, com o objetivo de caracterizar a população que será objeto deste estudo. Neste item, analisa-se ainda, especificamente, os direitos dessa população e os problemas envolvidos na sua efetividade.

Partindo deste ponto, através do levantamento de dados epidemiológicos, sociais e de atos presidenciais noticiados, o estudo relaciona os números de infectados e os prejuízos causados à população, desde a notificação do primeiro caso de coronavírus no Brasil, traçando um paralelo entre a postura do governo e a gravidade da pandemia no país.

Por fim, o quarto tópico indica algumas das medidas administrativas realizadas pelo Estado brasileiro para a proteção de alguns grupos da população vulnerável, após o início da pandemia, verificando a efetividade dessas medidas.

Percorridos os tópicos apresentados, espera-se concluir se o Estado brasileiro adotou as medidas necessárias e obrigatórias para a proteção dos grupos em vulnerabilidade social.

Importante destacar que esta discussão extrapola as fronteiras do estudo doutrinário-jurídico, estando presente temáticas atuais, quanto à necessidade de garantia dos direitos fundamentais sociais, frente a situações de crise, como a pandemia de coronavírus.

\section{GRUPOS VULNERÁVEIS: QUEM SÃO?}

Mesmo que o coronavírus não faça distinção entre pessoas com base em seu gênero, classe ou raça, a contenção de seus impactos é diretamente afetada por estes fatores.

Deste modo, a análise da questão deve ser feita por meio de recortes de classe, gênero e raça, uma vez que diferentes indivíduos são atingidos de maneiras 
diferentes, devendo ser entendidos e tratados pelo Estado conforme suas particularidades.

Para contextualização, neste trabalho os termos minorias e grupos vulneráveis serão utilizados como sinônimos. Entretanto, cabe esclarecer a diferença entre estes termos.

Entende-se como indivíduos pertencentes à grupos em vulnerabilidade social tanto aqueles que não possuem uma única identidade que os definam (um traço específico em comum), sendo grupos compostos pela sociedade de maneira geral, estando suscetíveis de serem feridos, ofendidos ou atacados, quanto aqueles pertencentes a minorias (que possuem entre si traços culturais que originam grupos específicos). Acerca das minorias, Chaves ensina que:

A característica essencial desses grupos não se reduz a termos numéricos, e sim a certas feições estruturais básicas nas interrelações maioria-minoria, como a relação de poder, de acordo com a qual se verifica uma superioridade da "maioria" frente a uma minoria, inferior quanto ao poder. (CHAVES, 1970, p. 150).

Deste modo, a partir da análise feita por Elida Séguin acerca de minorias e grupos vulneráveis, tem-se que na luta pela sobrevivência, o mais forte que tende a vencer e a eliminar o mais fraco, com isso, perde-se a pluralidade social, (SÉGUIN, 2002). A autora ainda afirma que há íntima relação entre como as minorias e grupos vulneráveis são tratados e a garantia da plena democracia de um país.

Existe certa confusão entre minorias e grupos vulneráveis. As primeiras seriam caracterizadas por ocupar uma posição de não dominância no país onde vivem. Os grupos vulneráveis podem se constituir num grande contingente numericamente falando, como as mulheres, crianças e idosos. (...). $\mathrm{Na}$ prática tanto grupos vulneráveis quanto as minorias sofrem discriminação e são vítimas da intolerância, motivo que nos levou, no presente estudo, a não nos ater à diferença existente. (SÉGUIN, 2002, p. 12).

A conceituação acerca dos grupos vulneráveis é fundamental, tendo em vista que as desigualdades sociais afetam diretamente a questão sanitária e o enfrentamento ao coronavírus. No entanto, tendo em vista a amplitude dos grupos abarcados por estes termos, este estudo dará enfoque à população carcerária, negra, LGBT+ e hipossuficiente. 
A pandemia do COVID-19 atingiu o globo como um todo, impactando na vida de todos de maneiras diferentes. Para aqueles poucos que se encontram na parcela mais abastada e privilegiada da sociedade foram poucas as mudanças percebidas (por exemplo a privação à alguns de viagens internacionais ou de participar de grandes eventos esportivos), sendo que houve quem inclusive lucrou financeiramente com a situação de calamidade global.

Entretanto, para aqueles do outro lado da moeda, e não são poucos, a pandemia teve um impacto avassalador.

Os indivíduos que já sofriam em razão de sua situação de vulnerabilidade social foram os mais atingidos pela repercussão negativa causada pelo COVID-19, seja devido à dificuldade em manter-se em um trabalho formal, seja pelas péssimas condições de moradia ou pela dificuldade em ter acesso a serviço de saúde de qualidade (atingindo de maneira ainda mais alarmante as populações de rua). (ESTRELA et al., 2020).

Destaca-se que no momento inicial, em meados de março de 2020, os primeiros casos estavam associados às classes favorecidas economicamente, pois como esclarecido, o início da transmissão do novo coronavírus deu-se fora do Brasil, de modo que primeiro contaminou aqueles que estavam em viagens internacionais que posteriormente, ao retornarem ao Brasil, trouxeram consigo o vírus.

Contudo, a disseminação do vírus não se manteve entre os economicamente favorecidos, atingindo as comunidades periféricas principalmente por meio de empregadas domésticas, motoristas e entregadores que entraram em contato com patrões, passageiros e clientes infectados, levando o vírus para dentro de suas casas e comunidades.

\subsection{A proteção legal dos grupos vulneráveis}

Conforme se vê, as populações vulneráveis se encontram mais indefesas quando comparadas com o resto da sociedade. Assim, verifica-se a necessidade de criação de determinados direitos e políticas públicas que visem sanar as fragilidades dessa população, objetivando igualá-la aos demais. Nesse sentido, observa-se a aplicação dos direitos sociais. 
Estes direitos, também conhecidos como direitos econômicos, sociais e culturais, surgiram efetivamente com o advento da segunda geração (ou dimensão) dos direitos fundamentais, que trata sobre os direitos coletivos como os direitos à saúde, à educação e à seguridade social.

Assim, os direitos sociais se manifestam com o objetivo de efetivar a suposta igualdade existente entre os seres humanos. Em razão disso, busca diminuir o abismo entre os membros da sociedade ao conceder maior proteção e garantia de direitos àqueles que não possuem sequer o básico para viver:

[...] o Estado cria normas que expressamente preveem direitos anteriormente só desfrutados por aqueles a quem as condições de vida permitiam. Por meio dos Direitos de Segunda Geração, o Estado concede direitos basilares a todos.[...] Em resumo, os direitos sociais, embora sejam destinados a todos universalmente, foram criados como forma de corrigir um desequilíbrio decorrente da falta de limites nas liberdades individuais, beneficiando, assim, os que realmente necessitam por não conseguir obtêlos pelas próprias forças. (AVANCI, [2014], [p. 13-14]).

Dessa forma, analisando-se o objetivo dos direitos sociais, observa-se a relação entre estes e os grupos vulneráveis, sendo que tais indivíduos devem ter a oportunidade de se valer destes direitos e, consequentemente, da tutela por parte do Poder Público para diminuir a desigualdade existente em comparação às classes mais "prósperas" da sociedade.

Ocorre, no entanto, que a efetividade desses direitos para a proteção dos grupos vulneráveis encontra óbice na sua forma de aplicação programática, ou seja, que não determina a aplicação integral desses direitos em um só momento, mas uma evolução conforme a possibilidade do Estado (MARTINS, 2020, p. 166). Essa situação permite que o Estado se utilize do princípio da reserva do possível, também conhecido como mínimo financeiramente possível, tanto para justificar a ausência de direitos fundamentais para a concretização do mínimo existencial aos grupos vulneráveis, quanto para legitimar a prestação de serviços falhos e insuficientes para atender toda a população. (SILVA; CARVALHO, 2020).

Destaca-se, nesse sentido, que previamente a pandemia de coronavírus, os direitos sociais já lidavam com tentativas de retrocesso no Brasil, especialmente quanto ao direito à saúde (AMBROGI; MEDEIROS; SOUZA JUNIOR, 2020) e à educação (ANDRÉA; GUNDIM, 2020). Em razão disso, com o advento da pandemia e 
os impactos no Brasil, principalmente financeiros, se faz necessário um maior acompanhamento quanto aos direitos dessa população, visando impedir atos governamentais que limitem o amparo aos grupos que se encontram em vulnerabilidade social.

\section{A PANDEMIA DE CORONAVÍRUS E SEUS REFLEXOS NO BRASIL}

Conforme informações constantes no site do Ministério da Saúde (BRASIL, 2020a), foi em meados de 1960 que os primeiros coronavírus, causadores de infecções respiratórias, foram identificados em humanos. Ao longo da vida, a maioria das pessoas infecta-se com os coronavírus comuns (alpha coronavirus 229E, NL93, beta coronavírus OC43 e HKU1), sendo que são as crianças as com maiores chances de se infectar.

Tendo os primeiros casos registrados do novo coronavírus (nCoV-2019) em dezembro de 2019, na China, no Brasil, o primeiro caso confirmado ocorreu apenas em fevereiro de 2020.

Desde 11 de março de 2020, quando a Organização Mundial da Saúde declarou a pandemia de coronavírus, até a data de 25 de novembro de 2020, foram contabilizados o total de 32.115.194 (trinta e dois milhões, cento e quinze mil e cento e noventa e quatro) casos e 980.046 (novecentos e oitenta mil e quarenta e seis) óbitos. (WORLD HEALTH ORGANIZATION, 2020).

Do total de casos, mais de quinze milhões ocorreram nas américas, sendo este o continente com maior número de casos até então, seguido pela Ásia e pela Europa, com mais de cinco milhões de casos confirmados cada.

Até o mês de setembro de 2020, o Brasil estava entre os três países com maior número de infectados e de mortos (4.624.885 e 138.977 respectivamente), junto com os Estados Unidos da América (6.868.828 casos e 200.725 óbitos) e a Índia (5.818.570 casos e 92.290 óbitos).

Como meio para conter a propagação da pandemia, o Brasil, em um primeiro momento, sugeriu que recém-chegados de países com altos índices de infectados realizassem quarentena, mesmo quando ainda não havia nenhum óbito no país. Contudo, como exposto anteriormente, o vírus não foi contido e se espalhou das 
classes mais altas que retornavam de viagem até chegar às populações mais vulneráveis, impactando tanto a vida desses indivíduos, quanto o país, como um todo.

\subsection{Economia e Desemprego}

Os impactos causados pela pandemia do coronavírus no Brasil foram além da área da Saúde, gerando instabilidade econômica e aumento das taxas de desemprego no país.

Segundo o Instituto Brasileiro de Geografia e Estatística (IBGE, 2020), no segundo trimestre de 2020 o número de desempregados passou a marca dos doze milhões e a taxa de desemprego passou os $11 \%$, com tendência de desocupação em alta desde o último trimestre de 2019.

Devido à pandemia, entre maio e agosto de 2020, mais de oito milhões de pessoas encontravam-se trabalhando de forma remota. Em agosto de 2020 já eram mais de três milhões de pessoas afastadas do trabalho devido ao distanciamento social. Ainda, com o aumento do desemprego e a dispensa dos empregos formais, os trabalhadores informais chegaram a representar $39,9 \%$ da população ocupada, com contingente de 36,8 milhões de pessoas.

Para criar barreiras contra a disseminação do vírus, foi sancionada a Lei n. ${ }^{0}$ 13.979/2020 (BRASIL, 2020b), que dispõe sobre as medidas para enfrentamento ao coronavírus, prevendo medidas a serem adotadas para contenção do vírus, como o isolamento e a quarentena.

Outro impacto causado na economia brasileira foi a crescente alta do dólar americano em relação ao real brasileiro, chegando ao recorde histórico de quase $\mathrm{R} \$ 5,90$ (cinco reais e noventa centavos). 
Gráfico - Oscilação do preço do dólar americano em comparação com o real brasileiro.

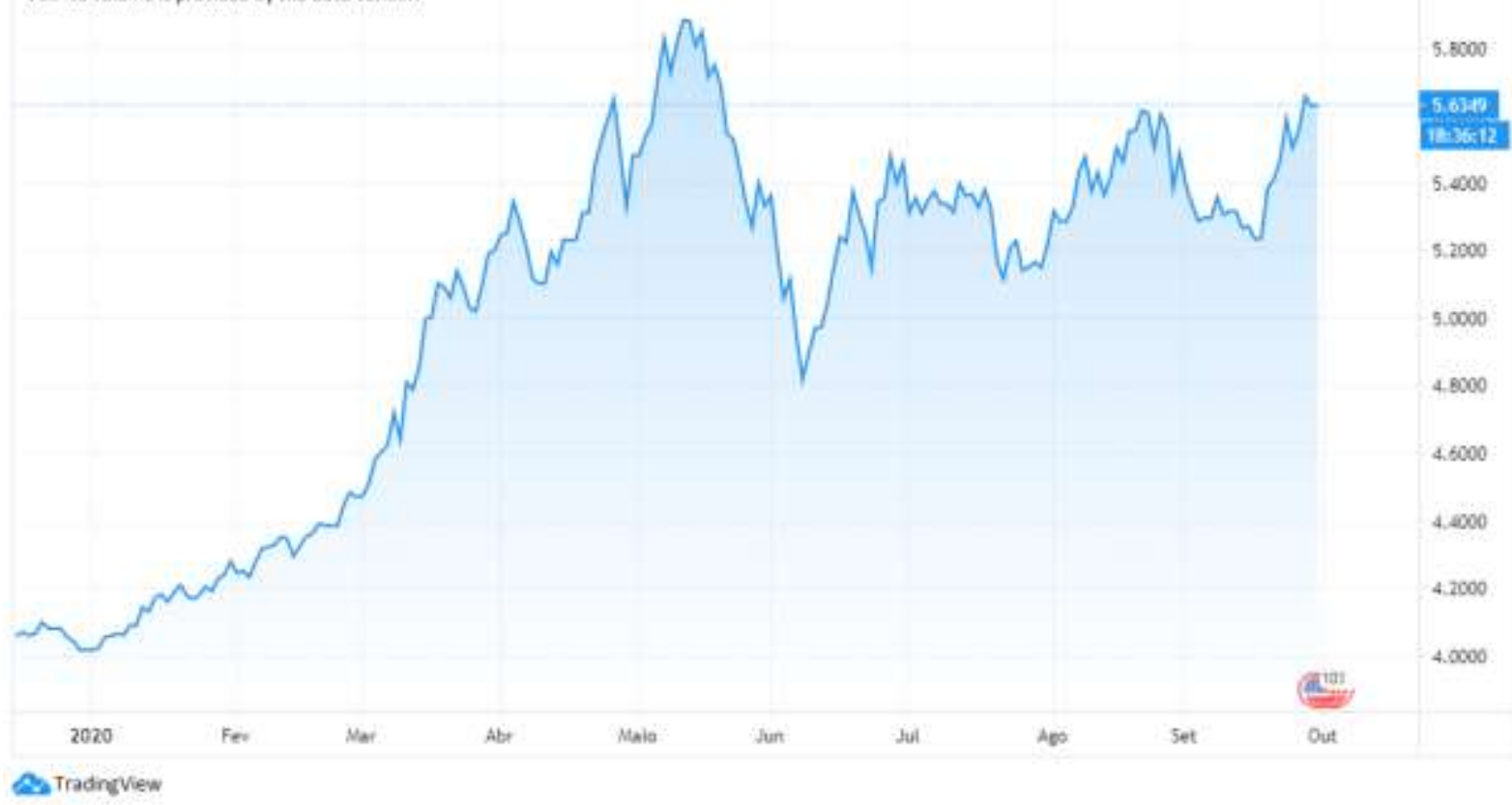

Fonte: (TRADINGVIEW, 2020).

A tendência de alta no preço do dólar americano, desde o início de 2020, gera impactos em toda a sociedade brasileira, elevando os preços de diversos bens de consumo. Quem mais sofre com as variações e inflação do mercado financeiro são aqueles que estão na camada mais vulnerável da sociedade, razão pela qual, em resposta à tendência de desemprego e queda na renda dos brasileiros, o Governo Federal concedeu um benefício financeiro destinado aos trabalhadores informais, microempreendedores individuais (MEI), autônomos e desempregados, denominado auxílio emergencial. Conforme pesquisa do IBGE, cerca de 29 milhões de domicílios brasileiros receberam em junho de 2020 algum benefício do governo em resposta ao coronavírus. (CAIXA ECONÔMICA FEDERAL, 2020).

\subsection{Fake News no contexto do COVID-19}

Com o advento da internet, tornou-se possível o compartilhamento e o acesso praticamente infinito à informação, podendo ser acessadas por qualquer um 
com acesso à rede mundial de computadores. Contudo, neste espaço virtual facilitouse também a propagação de falsas notícias e informações, sendo que nem sempre aquele que escreve ou recebe a notícia faz a checagem de fatos em fontes confiáveis.

O debate acerca das fake news, com tradução literal para o português como notícia falsa, não teve início após a disseminação do coronavírus. Desde o período das eleições presidenciais de 2018, o debate acerca do perigo apresentado pela propagação de notícias falsas já tem seu espaço e preocupa a muitos.

Falsas notícias acerca do coronavírus disseminam desinformação e medo na população, espalhando-se pelas redes em alta velocidade. Pennycook e Rand (2019) trazem que as mídias sociais são grandes impulsionadoras das notícias falsas, indicando ainda que os indivíduos têm maior tendência a acreditar em notícias falsas quando estas estão de acordo com suas ideologias pessoais, dificultando a comunicação e tornando-a duvidosa.

\subsection{Atos e falas presidenciais durante a pandemia de COVID-19}

Superada a análise quanto às desigualdades que permeiam a sociedade, os impactos na economia e a influência da disseminação de notícias falsas acerca da pandemia, é necessária a contextualização política e socioeconômica.

Neste sentido, faz-se uma comparação quanto aos posicionamentos do atual presidente Jair Messias Bolsonaro e o número de infectados e mortos no país, desde o primeiro caso no Brasil até o discurso do presidente na ONU, em setembro de 2020. 
Tabela - Quadro comparativo entre as falas presidenciais e os números de infectados e mortos durante a pandemia do coronavírus.

\begin{tabular}{|c|c|c|c|}
\hline DATA & $\begin{array}{l}\text { CASOS } \\
\text { ACUMULAD } \\
\text { OS POR DIA } \\
\text { NO BRASIL }\end{array}$ & $\begin{array}{l}\text { ÓBITOS } \\
\text { ACUMULAD } \\
\text { OS POR DIA } \\
\text { NO BRASIL }\end{array}$ & PRONUNCIAMENTOS DO PRESIDENTE JAIR MESSIAS BOLSONARO \\
\hline $26 / 02 / 2020$ & 1 & 0 & PRIMEIRO CASO NO BRASIL \\
\hline 09/03/2020 & 25 & 0 & $\begin{array}{l}\text { "Tem a questao do coronavírus também que, no meu entender, está } \\
\text { superdimensionado o poder destruidor desse vírus" }\end{array}$ \\
\hline $17 / 03 / 2020$ & 291 & 1 & $\begin{array}{l}\text { "Esse virus trouxe uma certa histeria. Tem alguns governadores, no meu entender, } \\
\text { posso estar errado, que estão tomando medidas que vão prejudicar e muito a nossa } \\
\text { economia" }\end{array}$ \\
\hline $24 / 03 / 2020$ & 2201 & 46 & $\begin{array}{c}\text { "No meu caso particular, pelo meu histórico de atleta, caso fosse contaminado pelo } \\
\text { vírus, não precisaria me preocupar. Nada Sentiria. Seria, quando muito, acometido } \\
\text { de uma qripezinha ou resfriado." }\end{array}$ \\
\hline $29 / 03 / 2020$ & 4267 & 136 & $\begin{array}{c}\text { "Vamos enfrentar o vírus com a realidade. É a vida, todos nós vamos morrer um } \\
\text { dia" }\end{array}$ \\
\hline $12 / 04 / 2020$ & 22206 & 1225 & $\begin{array}{c}\text { "Quarentena dias depois, parece que está começando a ir embora a questão do } \\
\text { vírus" }\end{array}$ \\
\hline $28 / 04 / 2020$ & 72149 & 5050 & "E daí? Lamento. Quer que eu faça o quê? Eu sou Messias, mas não faço milagre" \\
\hline $20 / 05 / 2020$ & 291579 & 18859 & "Quem é de direita toma cloroquina, quem é de esquerda, Tubaína" \\
\hline $02 / 06 / 2020$ & 555383 & 31199 & "A qente lamenta todos os mortos, mas é o destino de todo mundo" \\
\hline $10 / 06 / 2020$ & 772416 & 39680 & $\begin{array}{l}\text { "Se quiser falar, sai daqui, por que já foi ouvida. Cobre do seu governador. Sai } \\
\text { daqui" }\end{array}$ \\
\hline $03 / 07 / 2020$ & 1539081 & 63174 & $\begin{array}{l}\text { Presidente veta obrigatoriedade do uso da máscara de proteção individual em } \\
\text { órgãos e entidades públicas e em estabelecimentos comerciais, industriais, templos } \\
\text { religiosos, instituições de ensino e demais locais fechados em que haja reunião de } \\
\text { pessoas. Fonte: Aqência Senado }\end{array}$ \\
\hline $31 / 07 / 2020$ & 2662485 & 92475 & $\begin{array}{c}\text { Eu estou no grupo de risco. Agora, eu nunca negligenciei. Eu sabia que um dia ia } \\
\text { pegar. Infelizmente, acho que quase todos vocês vão pegar um dia. Tem medo do } \\
\text { quê? Enfrenta! (...) Lamento. Lamento as mortes. Morre gente todos os dias de uma } \\
\text { série de causas. É a vida, é a vida." }\end{array}$ \\
\hline $06 / 08 / 2020$ & 2912212 & 98493 & $\begin{array}{l}\text { "A gente lamenta todas as mortes, vamos chegar a } 100 \text { mil, mas vamos tocar a vida } \\
\text { e se safar desse problema" }\end{array}$ \\
\hline $22 / 09 / 2020$ & 4591604 & 138108 & Discurso Bolsonaro na ONU \\
\hline
\end{tabular}

Fonte: Autoras (2020) ${ }^{1}$

Em primeira análise, ressalta-se que mesmo com o contínuo aumento do número de casos confirmados e de óbitos no país, o presidente mantém o posicionamento negacionista quanto a gravidade do coronavírus, sendo que, ao manifestar-se contrariamente ao isolamento social, levou à queda nos índices de isolamento no Brasil. Nesse sentido, o estudo realizado por Ajzenman, Cavalcanti e Da Mata (2020), analisou os impactos da liderança durante o momento de crise atual acerca do coronavírus, indicando que os cidadãos podem ignorar as melhores indicações médicas, sendo vital, dessa forma, o papel do líder de estado para coordenar as informações corretamente. Os autores ainda documentaram uma

\footnotetext{
${ }^{1}$ Dados de infectados e óbitos obtidos por meio das Secretarias Estaduais de Saúde do Brasil, 2020, encontrados no site. (BRASIL, 2020b).
} 
significante queda do distanciamento social nos grupos de apoiadores do atual governo.

Em contrapartida à fala do presidente em 24 de março de 2020, um estudo realizado por pesquisadores do Centro Universitário Estadual da Zona Oeste (Uezo) e do Instituto Nacional de Traumatologia e Ortopedia Jamil Haddad (Into) (HULL; LOOSEMORE; SCHWELLNES, 2020) desmente a ideia de que atletas sejam mais resistentes à infecção pelo novo coronavírus, indicando que a alta intensidade de treino dos atletas profissionais pode aumentar a ventilação alveolar e tornar maior o risco de infecção viral no trato respiratório.

Em seus pronunciamentos o presidente trata a doença com eufemismos, reduzindo a gravidade da pandemia, posicionando-se a favor do uso da hidroxicloroquina, mesmo sem estudos que comprovem a eficácia do remédio no tratamento da doença. Inclusive, estudo colaborativo mundial para testar a efetividade de diferentes medicamentos no combate ao coronavírus, denominado projeto SOLIDARITY, em junho de 2020 (ORGANIZAÇÃO PAN-AMERICANA DA SAÚDE, 2020a), anunciou que as pesquisas acerca da hidroxicloroquina foi interrompida, com a conclusão de que o uso do medicamento não reduz a mortalidade de pacientes com COVID-19 hospitalizados.

A Organização Pan-Americana da Saúde em conjunto com a Organização Mundial da Saúde (ORGANIZAÇÃO PAN-AMERICANA DA SAÚDE, 2020b) publicaram texto orientando sobre o uso de máscaras como uma das estratégias para prevenção e controle de propagação do coronavírus, em contradição ao veto do presidente à obrigatoriedade do uso de máscaras em órgãos e entidades públicas e em estabelecimentos comerciais, industriais, templos religiosos, instituições de ensino e demais locais fechados em que haja reunião de pessoas.

Em discurso realizado na Organização das Nações Unidas em setembro de 2020 (AGÊNCIA BRASIL, 2020), o presidente Jair Bolsonaro fez afirmações acerca do auxílio emergencial (indicando ter sido pago o valor de mil dólares por cidadão), combate ao coronavírus, decisão do Supremo Tribunal Federal quanto ao enfrentamento ao coronavírus pelos governadores dos estados (eximindo-se da 
responsabilidade, mesmo que a decisão judicial tenha sido no sentido da competência comum para legislar acerca do tema), entre outros temas².

Em conclusão, a atual gestão da saúde e da crise sanitária na qual se encontra o país é deficiente e envolta em falsas informações. Como observado acima, são fatores determinantes a falta de enfrentamento sério e o descumprimento de orientações das autoridades de saúde, tanto nacionais quanto internacionais.

\section{MEDIDAS DO ESTADO BRASILEIRO NA PROTEÇÃO DOS GRUPOS VULNERÁVEIS EM TEMPOS DE PANDEMIA}

Conforme exposto, a população vulnerável é impactada de forma social, material e psicológica, devido à exclusão causada por motivos históricos, financeiros, religiosos, de orientação sexual, raça, entre outros.

Assim, quando do surgimento do coronavírus, essa população foi ainda mais impactada devido à sua própria condição. A falta de acesso à internet, equipamentos tecnológicos, saneamento básico nas comunidades, dificuldades financeiras e desemprego foi apenas alguns dos prejuízos verificados. Nesse sentido, estudos comprovam que os marcadores de raça, gênero e classe tornam o indivíduo ainda mais vulnerável perante a pandemia do coronavírus. (ESTRELA et al., 2020).

Diante disso, sendo o desenvolvimento nacional o preceito fundamental da República Brasileira, conforme a Carta Magna, cabe ao Estado aplicar políticas públicas que efetivamente resguardem os direitos fundamentais e sociais de todos. Ou seja, deveria o poder público adotar medidas direcionadas e pensadas especificamente aos diferentes grupos em situação de vulnerabilidade social.

Ressalta-se que na ausência da prestação de um direito já implementado, ou que esteja sendo negado, pode a parte lesada requerer sua prestação por via jurisdicional, buscando a obrigação do Estado ao cumprimento do seu dever, seja uma obrigação positiva ou negativa.

\footnotetext{
${ }^{2} \mathrm{O}$ presidente também se manifestou quanto às queimadas no país (culpando índios e caboclos), o derramamento de óleo no nordeste (acusando a Venezuela) e a suposta cristofobia (entendida como o preconceito direcionado aos evangélicos). (AGÊNCIA BRASIL, 2020).
} 


\subsection{Cartilhas}

Em atenção ao aumento da vulnerabilidade da população diante da pandemia, verifica-se que o governo brasileiro, por meio de diversos órgãos públicos, realizou a publicação de cartilhas que trazem as formas de proteção do vírus, com enfoque para cada grupo específico. Assim, destaca-se a cartilha "Mulheres na COVID-19", publicada pela Secretaria Nacional de Políticas para as Mulheres (SNPM), em colaboração com o Conselho Nacional dos Direitos da Mulher (BRASIL, 2020c), e a cartilha com enfoque na população LGBT+, publicada pelo Ministério da Mulher, da Família e dos Direitos Humanos. (BRASIL, 2020d).

Não obstante a criação das cartilhas possa ter como objetivo o alcance às populações vulneráveis, observa-se no conteúdo das mesmas diversas informações que perpetuam os preconceitos sociais sofridos por esses grupos.

Em primeiro lugar, destaca-se o número de páginas de cada documento. Enquanto a cartilha voltada para as mulheres possui 68 páginas, a voltada para a população LGBT+ possui apenas 3.

No que tange às informações constantes nos respectivos documentos, ambos trazem os dados básicos quanto à proteção contra o coronavírus, como lavar as mãos e manter distância. No entanto, a cartilha para as mulheres trata ainda sobre como entreter as crianças no período de distanciamento social, assim como explicar a elas o risco causado pelo vírus, alimentos indicados que fortalecem o sistema imunológico, informações empresariais e um grande levantamento quanto aos serviços disponíveis para a proteção da mulher, principalmente em caso de violência doméstica e sexual.

Por outro lado, verifica-se na cartilha voltada para a população LGBT+, o enfoque principalmente em informações sobre tratamento de HIV, e ISTs, o compartilhamento de objetos como "bitucas" e "copos", e a indicação de início de trabalho home office para aqueles que exerciam cargos em bares e boates, ou profissões autônomas.

Assim, os tratamentos dispensados a esses dois grupos populacionais demonstram a perpetuação, pelos órgãos governamentais, dos preconceitos gerados pela sociedade. Isso porque entende que as dicas de cuidados com crianças devem 
ser indicadas apenas para as mulheres, enquanto as informações para a população LGBT+ focam principalmente no tratamento de doenças sexualmente transmissíveis, como a AIDS.

\subsection{Proteção da população carcerária}

Quando se fala de população carcerária no Brasil, faz-se importante, primeiramente, relembrar a situação desse grupo já em período anterior à pandemia: O país é o terceiro no número de população carcerária no mundo, com um total de 748 mil pessoas encarceradas em 2019, conforme dados do Departamento Penitenciário Nacional (DEPEN) (PURGATO, 2020). Em razão disso, encontram-se situações insalubres em diversos presídios, com superlotação de celas, falta de água e produtos para higiene básica.

Com o início da pandemia, verificou-se a impossibilidade de cumprimento das recomendações dos órgãos de saúde dentro dos presídios. Assim, em 17 de março de 2020, o Conselho Nacional de Justiça (CNJ) emitiu recomendações aos tribunais e juízes, em que indicava a realização de ações para a diminuição da população carcerária através da revogação de prisões provisórias de mulheres gestantes, lactantes, mães ou pessoas responsáveis por crianças de até 12 anos ou pessoas com deficiência, assim como idosos, indígenas, pessoas com deficiência ou que se enquadrem no grupo de risco. (CONECTAS DIREITOS HUMANOS, 2020).

No entanto, apesar dos atos exercidos pelo $\mathrm{CNJ}$, em uma pesquisa realizada pela Faculdade Getúlio Vargas (FGV) (SETE, 2020) com familiares de detentos no Estado de São Paulo entre 25 de junho e 4 de julho de 2020, 69,6\% informaram não ter qualquer informação ou contato com o parente encarcerado. Ainda, 54,1\% manifestaram preocupação com a saúde do preso, e também apontaram a preocupação em relação ao seu parente estar passando fome dentro do presídio, devido à interrupção das visitas. Por fim, $96 \%$ das famílias informaram não ter recebido qualquer auxílio da Secretaria de Administração Penitenciária (SAP).

Diante dos dados divulgados, verifica-se a necessidade de atenção à essa população. Apesar de seu encarceramento e distanciamento da sociedade, tal situação não impede o contato com o vírus por meio de funcionários do presídio e 
suprimentos recebidos. Ainda, é importante ressaltar a responsabilidade do Estado na proteção da saúde e segurança do detento enquanto estiver sob sua tutela. Assim, em caso de descumprimento com seus deveres, cabe ao Estado responder civilmente pelos danos causados aos indivíduos encarcerados.

\subsection{Hospitais de campanha}

Diante do rápido aumento do número de casos de COVID-19 notificados no Brasil, o governo se mobilizou na melhoria do Sistema Único de Saúde para o recebimento dos infectados e suspeitos de estarem contaminados com o vírus. Nesse sentido, iniciou-se a implantação de diversos hospitais de campanha ao redor do país, com estrutura completa para atendimento da população de suspeitos por contaminação pelo coronavírus.

Essa proposta para melhoria da saúde pública no Brasil ocasiona, ainda hoje, diversas discussões quanto ao seus benefícios e prejuízos. Isso porque, embora alguns hospitais de campanha tenham sido essenciais para o tratamento da população, outros foram fechados antes mesmo de atender um paciente.

Desde o início da pandemia, avalia-se que foram instalados cerca de 70 hospitais por todo o país. No entanto, em razão da urgência no aumento dos leitos e do atendimento, diversos desses locais foram instalados sem o devido planejamento (BIDERMAN, 2020). O estudo da implantação dos hospitais de campanha ajudaria cada Estado a definir a necessidade de tratamentos específicos. Ressalta-se, que devido à falta de padronização do vírus, era necessário estudar cada região e o seu sistema de saúde individualmente. Isso se demonstra com a análise do hospital de campanha instalado em Belo Horizonte, que consumiu R\$ 2 milhões de reais, e encerrou suas atividades antes de realizar atendimentos. Tal situação ocorreu pois o acréscimo ao sistema de saúde possuía 740 leitos de enfermaria, no entanto, o município enfrentou a falta de leitos de unidade de terapia intensiva. (CRUZ, 2020).

Outra situação que impactou o planejamento dos hospitais de campanha foram as suspeitas de corrupção nas suas construções. Nesse sentido, ensina Fabrício Polido: 
Há consenso em admitir-se que a corrupção 'sistêmica' sobrecarrega contas públicas e o funcionamento democrático de instituições, oferecendo bases para apropriação privada de recursos públicos que deveriam ser investidos na elaboração e implementação de políticas orientadas para expansão de direitos fundamentais. Nesse sentido, gera externalidades sociais variadas, prejudica diretamente as camadas mais vulneráveis da população, em geral as que mais dependem de políticas de promoção de direitos sociais, econômicos e culturais. (POLIDO, 2018, p. 291).

Assim, verifica-se o grande prejuízo causado à população, principalmente à população vulnerável, devido à ausência de planejamento do governo na melhoria da saúde pública em razão da pandemia.

\subsection{Auxílio Emergencial}

Outra importante implementação do governo durante o período de pandemia, trata-se do pagamento de auxílio emergencial, que visava a diminuição do impacto econômico causado pelo vírus. Assim, a proposta inicial do auxílio visava o recebimento de 3 parcelas de $R \$ 600,00$ (seiscentos reais) ou de $R \$ 1.200,00$ (mil e duzentos reais), a depender da formação familiar do indivíduo. O programa possibilitou o acesso ao montante por todos os trabalhadores de baixa renda, incluindo os desempregados, que estivessem cobertos pela Previdência Social.

Em teoria, o auxílio deveria proporcionar suporte financeiro para a população vulnerável, ou seja, àqueles que já estivessem desempregados, que perdessem o emprego em razão da quarentena imposta como prevenção ao coronavírus, ou que exercessem trabalho autônomo (NATALINO; PINHEIRO, 2020). No entanto, assim como os hospitais de campanha, o curto tempo para planejamento influenciou no desenvolvimento de problemas que afetassem a política implementada.

Em primeiro lugar, o modo de cadastro e pagamento totalmente online dificultou o acesso de diversas pessoas ao auxílio. Ainda, a forma de cadastro por meios não presenciais e ausência de órgãos reguladores, permitiu a atividade de hackers e estelionatários, que cadastraram pessoas que possuíam o direito ao auxílio, utilizando contas que não eram de titularidade deste beneficiário. (SCHYMURA, 2020).

Dessa forma, se por um lado o auxílio beneficiou determinados indivíduos, por outro lado, possibilitou a atividade ilegal de fraude em políticas sociais. Ainda, 
destaca-se a possibilidade de aumento nos gastos públicos diante dos possíveis processos judiciais decorrentes do benefício, seja na defesa em processos em que o auxílio foi negado, seja contra os requisitantes que receberam o auxílio sem cumprir os requisitos, e portanto devem devolvê-lo, ou até mesmo em virtude da diferença de valor entre o auxílio fornecido, e o informado pelo presidente em discurso na ONU, em que manifestou haver pago US\$ 1.000 (mil dólares) para cada beneficiário. (FRAGÃO, 2020).

\section{CONCLUSÃO}

Após reflexão acerca dos atos realizados pelo Estado para proteção dos indivíduos em situação de vulnerabilidade, conclui-se que a atuação deste foi deficiente.

Isto pois, não obstante a característica programática dos direitos sociais uma vez estabelecidos, estes se encontram protegidos pela proibição de retrocesso. Assim, não poderia o Estado deixar de cumprir os direitos já implantados. Em um segundo momento, no caso dos direitos sociais que já são positivados na Constituição Federal, é dever do Estado protegê-los conforme determinado, independente da possível alegação de reserva do possível. Assim, não poderia o Estado omitir-se quanto ao direito à saúde, à vida e à dignidade humana da população, ou manifestar-se de forma a diminuir a proteção já existente.

No que tange às medidas tomadas pelos órgãos administrativos, verifica-se que a falta de planejamento impactou na aplicação das medidas governamentais, que em sua maioria ou se tornaram obsoletas (como no caso dos hospitais de campanha) ou não foram suficientes para a proteção da população (como se verifica em relação à população carcerária).

Não bastasse os problemas decorrentes da ausência de políticas públicas eficientes para diminuição da vulnerabilidade destes grupos ainda em momento anterior à pandemia de COVID-19, o país enfrenta problemas políticos e econômicos decorrentes de atos e falas irresponsáveis do presidente somados aos impactos causados pela crise sanitária. Em momentos como este, faz-se necessária a atuação do líder governamental como figura de confiança, que deve estabelecer as medidas a 
serem tomadas para a proteção de toda a sociedade. Tal situação não se verifica no Brasil, visto que por meio do levantamento de dados realizados no presente trabalho, demonstrou-se a existência de diversas divergências entre a postura do atual presidente e as orientações dos órgãos administrativos, o que divide a confiança da população e contribui para sua desinformação, gerando o aumento da vulnerabilidade dos grupos já desfavorecidos.

Ressalta-se, ainda, que na inobservância de seus deveres, principalmente quanto à segurança e ao direito à vida da população, pode o Estado ser acionado judicialmente para responder pelos danos causados por seus atos, sejam eles positivos ou negativos.

Portanto, analisadas as medidas tomadas, as falas presidenciais e as recomendações e diretrizes de enfrentamento ao coronavírus disponibilizadas pelos órgãos nacionais e internacionais da área da saúde, em comparação aos direitos dos grupos vulneráveis, pode-se observar que as estratégias do governo brasileiro não apenas não foram efetivas para frear a propagação do COVID-19, como incentivaram atitudes que elevaram as taxas de contaminação.

Tendo em vista que a crise sanitária e a pandemia do coronavírus ainda se encontra em andamento, não é possível concluir quanto a responsabilidade do governo (seja pelas medidas realizadas, ou a ausência delas) durante a pandemia. Assim, por meio da análise dos dados disponíveis até o momento, conclui-se pela ineficácia das medidas governamentais para efetiva proteção dos grupos em vulnerabilidade social.

\section{REFERÊNCIAS}

AGÊNCIA BRASIL. Veja a íntegra do discurso de Bolsonaro na 75a Assembleia Geral da ONU. Agência Brasil, Brasília, DF, 2020. Disponível em: https://agenciabrasil.ebc.com.br/politica/noticia/2020-09/veja-integra-do-discursode-bolsonaro-na-75a-assembleia-geral-da-onu. Acesso em 30 set. 2020.

AJZENMAN, N.; CAVALCANTI, T.; DA MATA, D. More than words: leaders' speech and risky behavior during a pandemic. Social Science Research Network, [S. I.], p. 1-47, 2020. Disponível em: https://papers.ssrn.com/sol3/papers.cfm?abstract_id=3582908. Acesso em: 27 set. 2020. 
AMBROGI, A.; MEDEIROS, T. D. C.; SOUZA JUNIOR, A. B. A nova face da judicialização do direito à saúde: tendências jurisprudenciais. In: REBÊLO, F. C. J. M.; SOUZA JUNIOR, A. B.; PONÇONI, M. (org.). Direitos sociais constitucionais: realidade e perspectivas. Londrina: Editora Thoth, 2020.

ANDRÉA, G. F. M.; GUNDIM, W. W. D. Novo regime fiscal (EC N. 95/16) e seus efeitos nas políticas públicas de educação no Brasil. In: REBÊLO, F. C. J. M.; SOUZA JUNIOR, A. B.; PONÇONI, M. (org.). Direitos sociais constitucionais: realidade e perspectivas. Londrina: Editora Thoth, 2020.

AVANCI, T. F. S. Acesso internacionalizado de direitos fundamentais: uma tônica inaugurada pela proteção ambiental. Revista Científica Integrada, [São Paulo], v. 1, n. 2, [p. 1-22], [2014]. Disponível em: https://www.unaerp.br/revista-cientificaintegrada/edicoes-anteriores/edicao-n-2-2014-1/1460-151-434-1-sm/file. Acesso em: 28 set. 2020.

BIDERMAN, I. Erros de planejamento prejudicam o desempenho de hospitais de campanha: avaliação aponta que certas estruturas foram criadas tardiamente e usadas de modo inadequado. Folha de São Paulo, São Paulo, 2020. Disponível em: https://www1.folha.uol.com.br/seminariosfolha/2020/08/erros-de-planejamentoprejudicam-o-desempenho-de-hospitais-de-campanha.shtml. Acesso em: 30 set. 2020.

BRASIL. Lei $\mathbf{n} .{ }^{\circ} \mathbf{1 3 . 9 7 9}$, de $\mathbf{6}$ de fevereiro de 2020. Dispõe sobre as medidas para enfrentamento da emergência de saúde pública de importância internacional decorrente do coronavírus responsável pelo surto de 2019. Brasília, DF: Presidência da República, 2020b. Disponível em: http://www.planalto.gov.br/ccivil_03/_ato20192022/2020/lei/l13979.htm. Acesso em: 30 set. 2020.

BRASIL. Ministério da Mulher, da Família e dos Direitos Humanos. Cartilha para a população LGBT+. [Brasília, DF]: MMFDH, 2020d. Disponível em: https://www.gov.br/mdh/pt-br/assuntos/noticias/20202/abril/Corona_banner_LGBT.pdf. Acesso em: 30 set. 2020.

BRASIL. Ministério da Mulher, da Família e dos Direitos Humanos. Mulheres na COVID-19. [Brasília, DF]: MMFDH, 2020c. Disponível em: https://www.gov.br/mdh/pt-br/assuntos/noticias/2020-2/abril/cartilha-orientamulheres-durante-a-pandemia-do-coronavirus/MulheresCOVID19.pdf. Acesso em: 30 set. 2020.

BRASIL. Ministério da Saúde. Painel coronavírus: atualizado em: 28/07/2020.

Coronavírus Brasil, [Brasília, DF], 2020b. Disponível em: https://covid.saude.gov.br/. Acesso em: 28 de set. 2020.

BRASIL. Ministério da Saúde. Resposta nacional e internacional de enfrentamento ao novo coronavírus. Ministério da Saúde, [S. I.], [2020a]. Disponível em: https://coronavirus.saude.gov.br/linha-do-tempo/. Acesso em 25 set. 2020. 
CAIXA ECONÔMICA FEDERAL. Auxílio emergencial. Caixa Econômica Federal, [S. l.], 2020. Disponível em:

https://www.caixa.gov.br/auxilio/PAGINAS/DEFAULT2.ASPX. Acesso em: 28 set. 2020.

CHAVES, L. G. M. Minorias e seu estudo no Brasil. Revista de Ciências Sociais, Fortaleza, v. 1, n. 1, p. 149-168, 1970. Disponível em: http://www.repositorio.ufc.br/handle/riufc/4487. Acesso em: 28 set. 2020.

CONECTAS DIREITOS HUMANOS. 5 medidas urgentes para a população carcerária durante a pandemia de coronavírus: 0 que dizem os principais órgãos internacionais de direitos humanos sobre a Covid-19 dentro das cadeias. Conectas Direitos Humanos, [S. I.], 2020. Disponível em: https://www.conectas.org/noticias/5medidas-urgentes-para-o-sistema-prisional-durante-a-pandemia-de-coronavirus. Acesso em: 30 set. 2020.

CRUZ, I. As brechas nos modelos de hospitais de campanha na pandemia. Nexo, [ $S$. l.], 2020. Disponível em: https://www.nexojornal.com.br/expresso/2020/09/11/Asbrechas-no-modelo-de-hospitais-de-campanha-na-pandemia. Acesso em: 30 set. 2020.

TRADINGVIEW. Dólar americano / real brasileiro. TradingView, [S. /.], 2020. Disponível em: https://br.tradingview.com/symbols/USDBRL/. Acesso em: 30 set. 2020.

ESTRELA, F. M. et al. Pandemia da Covid 19: refletindo as vulnerabilidades a luz do gênero, raça e classe. Ciência \& Saúde Coletiva, v. 25, n. 9, p. 3431-3436, 2020. Disponível em: https://doi.org/10.1590/1413-81232020259.14052020. Acesso em: 29 set. 2020.

FRAGÃO, L. Dona de casa vai à justiça pedir 1 mil dólares de auxílio emergencial citado por Bolsonaro. Revista Fórum, [S. I.], 26 de setembro de 2020. Disponível em: https://revistaforum.com.br/politica/dona-de-casa-vai-a-justica-pedir-1-mildolares-de-auxilio-emergencial-citado-por-bolsonaro/. Acesso em: 30 set. 2020.

HULL. J. H.; LOOSEMORE, M.; SCHWELLNES, M. Respiratory health in athletes: facing the COVID-19 challenge. The Lancet Respiratory Medicine, [S. I.], v. 85, p. 557-558, jun. 2020. Disponível em: https://www.thelancet.com/pdfs/journals/lanres/PIIS2213-2600(20)30175-2.pdf. Acesso em: 25 set. 2020.

IBGE. Trabalho: desocupação, renda, afastamentos, trabalho remoto e outros efeitos da pandemia no trabalho. IBGE, [S. l.], 2020. Disponível em: https://covid19.ibge.gov.br/pnad-covid/trabalho.php. Acesso em: 28 set. 2020.

NATALINO, M.; PINHEIRO, M. B. Nota técnica: proteção social aos mais vulneráveis em contexto de pandemia: algumas limitações práticas do auxílio emergencial e a adequação dos benefícios eventuais como instrumento complementar de política 
socioassitencial. Brasília, DF: IPEA, 2020. Disponível em:

http://repositorio.ipea.gov.br/handle/11058/9999. Acesso em: 30 set. 2020.

MARTINS, F. Direitos sociais em tempos de crise econômica. São Paulo: Saraiva Educação, 2020.

ORGANIZAÇÃO PAN-AMERICANA DA SAÚDE. Ongoing living update of potential COVID-19 therapeutics: summary of rapid systematic reviews. [S. I.]: PAHO, 2020a. Disponível em: https://iris.paho.org/handle/10665.2/52294. Acesso em: 28 set. 2020.

ORGANIZAÇÃO PAN-AMERICANA DA SAÚDE. Orientação sobre o uso de máscaras no contexto da COVID-19: orientação provisória, 5 de junho de 2020. [S. I.]: OPAS, 2020b. Disponível em: https://iris.paho.org/handle/10665.2/52254. Acesso em: 28 de set. 2020.

PENNYCOOK, G.; RAND, D. G. Lazy, not biased: susceptibility to partisan fake news is better explained by lack of reasoning than by motivated reasoning. Cognition, $[S$. l.], v. 188, p. 39-50, jul. 2019.

POLIDO, F. B. P. O combate global à corrupção e o direito internacional privado: primeiros esforços de uma sistematização necessária. In: FORTINI, C. (coord.). Corrupção e seus múltiplos enfoques jurídicos. Belo Horizonte: Fórum, 2018. p. 289-314.

PURGATO, V. População carcerária no Brasil tem direitos restringidos durante pandemia do coronavírus, avalia grupo de extensão. Pontifícia Universidade Católica de Campinas, [Campinas], 2020. Disponível em: https://www.puccampinas.edu.br/populacao-carceraria-no-brasil-tem-direitos-restringidos-durantepandemia-do-coronavirus-avalia-grupo-de-extensao/. Acesso em: 30 set. 2020.

SÉGUIN, E. Minorias e grupos vulneráveis: uma abordagem jurídica. Rio de Janeiro: Forense, 2002.

SETE em cada dez familiares não têm notícias de parente encarcerado na pandemia. Impacto, [S. l.], 16 de julho de 2020. Disponível em: https://www.impacto.blog.br/sem-categoria/sete-em-cada-dez-familiares-nao-temnoticias-de-parente-encarcerado-na-pandemia/. Acesso em: 30 set. 2020.

SCHYMURA, L. G. A dificuldade de o auxílio emergencial chegar em quem precisa. Conjuntura Econômica, [S. I.], 2020. Disponível em: http://bibliotecadigital.fgv.br/ojs/index.php/rce/article/viewFile/81580/77839. Acesso em: 30 set. 2020.

SILVA, D. R.; CARVALHO, D. Proibição do retrocesso social: perspectivas da realidade jurídico brasileira. In: REBÊLO, F. C. J. M.; SOUZA JUNIOR, A. B.; PONÇONI, M. (org.). Direitos sociais constitucionais: realidade e perspectivas. Londrina: Editora Thoth, 2020. 
WORLD HEALTH ORGANIZATION. WHO coronavirus disease (COVID-19) dashboard: data last updated: 2020/09/27. World Health Organization, [S. I.], 2020.

Disponível em: https://covid19.who.int/. Acesso em: 27 set. 2020. 